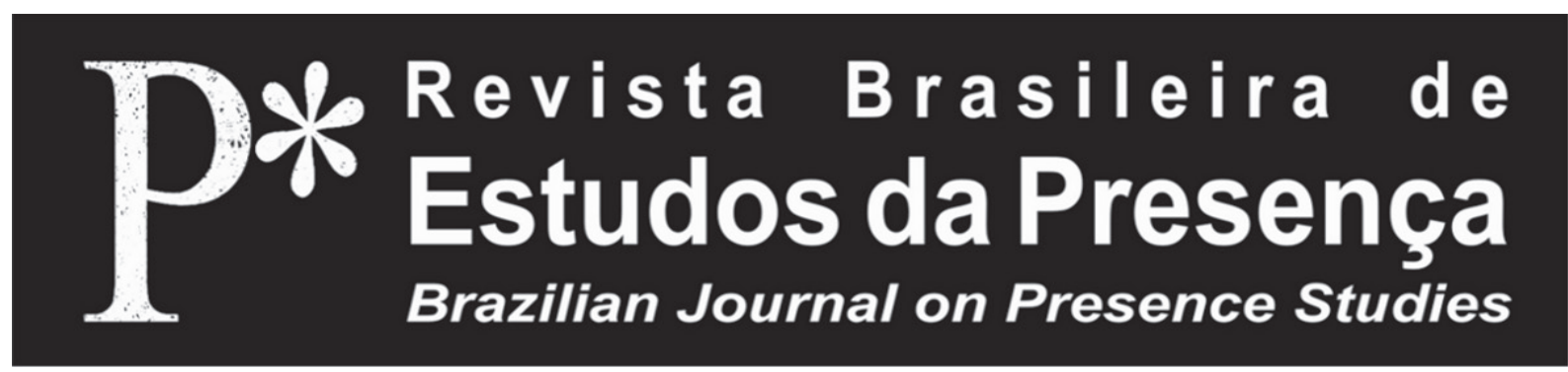

DOI - http://dx.doi.org/10.1590/2237-266039109

ISSN 2237-2660

\title{
Ações Comunicativas Corporais e seus Significados no Contexto Educacional
}

\author{
Djavan Antério \\ Universidade Federal da Paraíba - UFPB, João Pessoa/PB, Brasil
}

RESUMO - Ações Comunicativas Corporais e seus Significados no Contexto Educacional - Este artigo discute as ações comunicativas corporais, enfatizando a problemática da relação comunicativa entre os sujeitos. Referenciando o contexto educacional, discute-se a concepção amortizada do corpo no processo ensino-aprendizagem; a efetiva possibilidade teórica da inclusão de novos saberes docentes; e as contribuições advindas da linguagem corporal para um agir pedagógico. Pelo prisma da comunicação corporal, enfocam-se movimentos e seus significados, fomentando a premissa de que é possível transmitir e decodificar mensagens muitas vezes imperceptíveis à comunicação verbal. Defende-se, portanto, a linguagem corporal consciente, estabelecendo-se como um saber docente útil e eficaz.

Palavras-chaveEducação. Saber. Comunicação. Linguagem. Corpo.

ABSTRACT - Body Communicative Actions and their Meaning in the Educational Context - This article discusses the body communicative actions, emphasizing the issue of the communicative relationship among the subjects. Referencing the educational context, we discuss the dormant conception of the body in the teaching-learning process, the effective theoretical possibility of including new teaching knowledge, and the contributions of body language for pedagogical action. Through the prism of bodily communication, it is focused on movements and their meanings, promoting the premise that it is possible to convey and decode messages often imperceptible to verbal communication. Therefore, the conscious body language, establishing itself as a useful and effective teaching knowledge, is posited. Keywords:Education. Knowledge. Communication. Language. Body.

RÉSUMÉ - Actions du Corps Communicative et son Sens dans le Contexte Éducatif - Cet article décrit les actions de communication de corps, en insistant sur le problème de la relation communicative entre les sujets. Référencement le contexte éducatif, nous discutons de la conception du corps amorti processus d'enseignement-apprentissage, la possibilité théorique efficace d'intégrer de nouvelles connaissances de l'enseignement, et les contributions du langage du corps à l'action pédagogique. À travers le prisme de la communication corporelle, se concentrer jusqu'à mouvements et leurs significations, de promouvoir l'idée qu'il est possible de transmettre et décoder des messages souvent imperceptibles à la communication verbale. Il fait valoir, par conséquent, le langage du corps conscient, s'imposer comme une connaissance de l'enseignement utile et efficace. Mots-clés:Education. Savoir. Communication. Langue. Corps. 


\section{Introdução}

As discussões acerca do corpo, nos vários momentos históricos, tiveram diferentes focos e concepçóes. Contudo, independentemente da temática central, o corpo sempre provocou inquietaçóes. Por meio de uma leitura substancial por anos a fio, é possível encontrar concepçóes ora similares - de onde emergem pontos inclinados num mesmo direcionamento do corpo enquanto uma entidade material -, ora diversificadas, extraindo pensamentos transcendentais de um corpo desmitificado e mais subjetivo. Ainda, podem encontrar-se esferas mais comuns, como, por exemplo, o corpo enquanto matéria orgânica, objeto motriz, estrutura físico-biológica.

Buscando uma diferenciação interpretativa, levando em consideração aspectos subjetivos e transcendentais, como a própria linguagem corporal e as sensaçôes físicas e psíquicas, para este estudo, evidenciamos a concepçáo de corpo comunicativo. Isso significa incorporar a linguagem advinda de nossos gestos, nossas feiçōes, interpretar as nuanças informativas dos movimentos, das açóes (corporais). Partimos do princípio de que nossos movimentos falam, expressam e emitem informaçôes. Isso tanto para aqueles com quem nos relacionamos como com o próprio meio no qual estamos inseridos.

Como seres sociais, racionais, pensantes, lançamos informações constantemente através de nossas expressóes, nossas vontades, nossos anseios. Daí pensarmos o corpo tal como fonte de uma subjetividade rica em elementos não concretos, não racionalizáveis, porque vividos emocionalmente (Gomes-da-Silva, 2011). Por conseguinte, consideramos pertinente, sobretudo à esfera educacional, o investimento aprofundado na subjetividade que o corpo propicia. É nela e com ela que podemos nos fazer entender e compreender no mundo.

Intencionamo-nos a ampliar diferentes percepçóes do fenômeno corporal comunicativo e expressivo, cientificamente, traçando um caminho inverso/alternativo, um contraponto às imposiçóes presentes no senso comum ou mesmo aos estudos que navegam na concretude da objetividade, muitas vezes limitando a ótica interpretativa das açóes e dos movimentos.

Por meio de estudos anteriores (Antério, 2011; Antério; Gomesda-Silva, 2013) e do arcabouço teórico recorrido, constatamos a riqueza informativa do corpo, configurando-se como fonte comunicativa extremamente eficaz. Isso se deve, dentre outros aspectos, 
a sua composição rica em informaçóes lançadas por canais específicos: gestual, postural, espacial. É justamente nessa perspectiva que traçamos nossa caminhada, reconhecendo o valor comunicativo do corpo e suas implicaçóes ao meio. Da mesma forma, por estarmos inseridos no contexto educacional - tanto como docentes em busca de açóes interventivas mais humanizadas como sujeitos corporais que se conectam ao meio e aos outros -, preocupa-nos fomentar, na teoria e na prática, a concepção de corpo comunicativo.

A partir do dito, é importante reconhecer que o corpo oferece amplas condiçóes de revelar o sujeito intimo, ou seja, aquele que nem sempre se mostra na verbalizaçáo ou mesmo nas açóes condicionadas do dia a dia. Atentando-nos aos pormenores do corpo, é possível enxergar um pouco mais da pessoa humana, do sujeito encarnado na pele. Tal como aponta Medina (2001), o corpo é maior do que a sua função, devendo, portanto, ser considerado a partir de todas as suas dimensôes, sejam elas individuais, coletivas, sociais e/ou políticas.

Concebemos a comunicação corporal como capacidade de o sujeito comunicar-se pelo próprio ato de movimentar-se (linguagem náo verbal). Nisso, encontramos subsídios em Rector e Trinta, assimilando a comunicação verbal ou não verbal como um fenômeno humano, portanto social, no qual "[...] comunicar é manifestar uma presença na esfera da vida social. É estar-no-mundo-junto-com-outros” (1985, p. 8). Comunicar, neste caso, envolve uma perspectiva de partilha e de transferência de informação entre dois ou mais sujeitos/corpos.

Sobre o ato de movimentar-se, vale ressaltar a concepção que vai além do deslocamento do corpo, do movimento evidente de membros. Comungamos do pressuposto de que movimento está impregnado na ativação corporal que todos temos pelo simples fato de estarmos vivos. Por isso, entendermos que a simples açáo de respirar já se caracteriza como movimento. Nesta perspectiva, mesmo em se tratando de suas propriedades neurofisiológicas, biomecânicas e cognitivas, o movimento é visto tanto pelos seus determinantes exteriores aqueles evidentes aos olhos - como também pelos interiores - que acontecem dentro de nós, sobre uma confidencialidade extrema, às vezes até imperceptível.

Ao refletirmos sobre o contexto escolar, deparamo-nos com vícios e acomodaçóes acerca do valor corporal, sobretudo no que se refere à relação professor-aluno. Diante disso, Freire (2009) argumenta acerca da subutilizaçáo do corpo, expondo suas equivocadas 
exigências, principalmente em situaçóes em que se movimentar é requisito básico para o processo educativo, tal como nas aulas de educação física. Segundo o autor, a escola, portando-se inerte e desinteressada, persiste no marasmo pedagógico ineficiente, tradicional, descompassado com a evolução reflexiva das abordagens teóricopráticas da educação. Consequentemente, promove, danosamente, ações mecânicas e com rígidas funçôes disciplinares.

Ainda com Freire (2009), nota-se a impossibilidade do corpo ser explorado mais a fundo na escola, intervindo-o de forma lúdica, seja em sua movimentação intencional, seja na aleatória, espontânea, sem intenção aparente. Afinal, em determinadas fases da vida, somos "puro corpo" (Merleau-Ponty, 1994), movimentando-nos espontaneamente, brincando, extravasando as energias intensas, ligando-nos aos outros e ao meio com entrega absoluta de nós mesmos, vivendo efetivamente o corpo que somos.

Abordamos o movimento corporal como fonte de significados interpretados através de uma ótica diferenciada, apoiada e fundamentada na subjetividade desprendida das abstraçóes meramente performáticas de desempenho e/ou alto rendimento, senão cairíamos na conveniência prejudicial do entendimento engessado e limitado do corpo. Idealizamos este como condição existencial, avaliando, em contrapartida, insuficiente a interpretaçáo do movimento em si mesmo, isto é, a ação pela ação. Vamos um pouco mais além, reconhecendo, na ação, aspectos inerentes à condição humana, tais como a sensibilidade, a prazerosidade, a ludicidade, a diversidade emocional.

Por conseguinte, pesquisamos mantendo-nos distantes - porém não alheios - a perspectivas somente objetivas, como, por exemplo, a conduta laboral e as práticas desportivas que produzem um sujeito conforme as exigências de um sistema impiedoso, que visa, sobretudo, a sua motilidade. Partilhamos da ideia trazida por Bombassa ro e Vaz (2009), a qual explicita que, imerso num contexto estrategicamente sistemático, o sujeito é envolvido por um processo de subjetivação vinculado a um conjunto de condutas externamente determinadas.

Logo, preocupados em elucidar as açóes corporais inerentes ao processo de intervençáo docente, fazendo o sujeito agir com significação, propomo-nos a analisar, de forma crítica e reflexiva, a comunicação corporal a partir da gestualidade do educador, reconhecendo-o em seu próprio movimentar-se. Dessa forma, fomentamos 
a perspectiva do corpo como percepção e expressão inter-relacional do sujeito no mundo. Pensamos a ação comunicativa corporal do educador consigo mesmo, com os alunos e com o seu entorno. Discutimos o corpo comunicativo em sua inter-relação social com base nos pesquisadores Knapp e Hall (1999), Rector e Trinta (1985), Pease e Pease (2005), Picard (1986) e Weil e Tompakow (1986).

\section{Caminho Metodológico}

A pesquisa em questão se configura como descritiva e de abordagem qualitativa, por caracterizar o entendimento de um fenômeno, envolvendo significados, valores e atitudes, os quais possibilitam aprofundar as relaçóes dentro do processo social, como aponta $\mathrm{Mi}$ nayo (2001). Como eixo epistemológico, adotou-se o conceito de corpo como elemento perceptivo, ativo-expressivo e fundamental para a inter-relação comunicativa do sujeito consigo e com os outros, sendo esta uma dimensão da corporeidade. Isso implica afirmar que o corpo foi tratado, na pesquisa, como elemento subjetivo, além de suas perspectivas orgânicas, biológicas e estéticas.

Nossa pesquisa justifica-se pela importância em se trabalhar as diferentes possibilidades do corpo enquanto elemento prioritariamente presente no cotidiano do sujeito. Mas essas possibilidades não se fazem de forma natural, como se estivessem ligadas por/a ela. Elencamos uma visão transcendental da relação entre corpo e sujeito, considerando-os híbridos, não sendo possível um seguir sem o outro. Estabelecemos, ancorando-nos no arcabouço teórico recorrido, uma ruptura na lógica da separaçáo corpo e sujeito, na medida em que rompemos com o primado da concretude do ser material e propomos a subjetivação do corpo, compreendendo-o como linguagem, expressão e até mesmo espiritualidade.

Partindo desse bojo contextual, o presente artigo objetivou discutir os movimentos naturalmente realizados pelo professor no cotidiano de sua prática docente. Para isso, valemo-nos de obras literárias conceituadas sob a ótica da revisão sistemática, por permitirem integrar as relaçóes de um conjunto de pesquisas realizadas por determinadas intervençóes, podendo apresentar resultados semelhantes e/ou contrários, além de aproximar temas que precisam de evidências para estudos futuros. 
Além do mais, apoiamo-nos em eixos da fenomenologia, visto que esta apreende o sentido do mundo ou da história em seu estado nascente. E, ao localizar nosso problema na descoberta da significação originária do movimento do corpo humano no mundo, estamos dentro da análise existencial proposta pela fenomenologia. Em nosso entender, é extremamente complexo querer explicar que o ato de movimentar-se concebe sentido se não utilizarmos as noçóes subjetivas de teorias como a da corporeidade e a da comunicação corporal. Isso porque, para nós, “[...] a corporeidade é a condição existencial do corpo no mundo: modo da pessoa apresentar-se, mover-se, estar em ação ou inação em relação ao seu mundo circundante" (Gomesda-Silva, 2012, p. 140). Já no que se refere à comunicação corporal, entendemo-la como manifestação expressiva do corpo enquanto fonte de informação, isto é, a linguagem estabelecida através dos gestos, das expressóes, do modo de ser e estar no mundo (Antério, 2011).

Neste estudo, abordamos o movimento sob uma perspectiva que possibilitou sua ramificação. Para tanto, distinguimos três tipos de movimento a partir da teorização da comunicação corporal, mais especificamente estabelecendo uma interlocução com a gestualidade presente no movimento. São eles: (i) Movimento Mudo; (ii) Movimento Comunicativo; e (iii) Movimento Interativo. A seguir, detalharemos a base conceitual que diferencia cada um deles.

Entendendo o movimento enquanto linguagem, defendemos a tese de que, ao movimentarmo-nos, estamos exprimindo informação. Todavia, nem sempre tal informação pode ser captada, muito menos compreendida. Mais ainda, o que pode ocorrer é que essa informação náo seja percebida quando o movimento tem pouca (ou nenhuma) expressividade. É justamente nessa perspectiva que caracterizamos o tipo de movimento mudo. Este, apesar de ser composto de gestualidade, o que já o caracteriza como movimento, não tem em si (ao menos o suficiente) a expressividade necessária para torná-lo dizível. Ou seja, para que o movimento de fato transmita uma informação, é necessário um mínimo de elementos conectados à linguagem corporal. Isso significa que a transmissão de informação por meio do corpo está diretamente relacionada ao nível de expressividade do movimento.

Contudo, superando esse nível minimalista de expressividade, o movimento deixa de ser mudo para tornar-se comunicativo. Eis nosso segundo tipo de movimento. À luz de Corraze (1982) e Knapp e Hall (1999), creditamos ao ato de movimentar-se a devida importância 
na relação comunicativa entre sujeitos. Isso porque, munido de um arsenal de gestos naturalmente desenvolvidos ao longo da "vividade corporal" (Merleau-Ponty, 1994), o sujeito, enquanto corpo que é, cria canais de comunicação já através de seus próprios gestos. Estes, de maneira sugestiva, são indicativos do poder da linguagem não verbal. Logo, para que o movimento seja comunicativo, é preciso que a expressividade esteja suficientemente ancorada na gestualidade, provocando, assim, possibilidades reais de comunicação.

Por fim, esclarecendo o terceiro e último tipo de movimento, sobre os quais direcionamos nossa análise, temos o movimento interativo, que se caracteriza também com aspectos que compóem os dois tipos citados. Valendo-se de uma expressividade consideravelmente suficiente para a relação social, o movimento interativo é o mais completo em termos de possibilidades comunicativas. Isso se deve basicamente por conta de um fator primordial: a intencionalidade.

Partimos do princípio de que, ao movimentarmo-nos, produzimos, através da expressividade de nossos gestos, informaçôes que podem ou náo ser codificadas por outrem. Como bem falamos anteriormente, o fato de nossos gestos serem expressivos já garante o fator comunicacional da ação corporal. Entretanto, ao atentarmo-nos para a intenção desses gestos, de seus níveis de expressividade, ascendemos às possibilidades comunicativas não verbais do nosso corpo. Sendo assim, quando intencionalmente nos movimentamos e valorizamos nossos gestos e a expressividade que neles há, otimizamos a relação existente entre nós, os outros e o meio no qual estamos inseridos. Consequentemente, de forma natural e espontânea, ampliamos a interatividade entre os envolvidos.

Logo, se há intencionalidade, o movimento foi trabalhado com o intuito, no caso, de comunicar. Essa comunicação transforma relaçôes interativas em circunstâncias naturais e espontâneas, haja vista que a relação comunicativa entre sujeitos se dá constantemente por diferentes canais de comunicação, como gestual e postural. Por exemplo, mesmo parados, podemos lançar comunicação pelo olhar. Essa comunicação, por menor que pareça ser, é válida e eficaz, pois transmite a informação tal como fosse pela escrita ou mesmo pela fala.

\section{O Movimento como Linguagem Corporal}

Para iniciarmos um proveitoso diálogo com os conceitos trazidos pelos autores aos quais recorremos, é pertinente aclarar a essência 
significativa que temos em relação ao ato de movimentar-se. À luz de pensadores como Freire (1999), Hildebrandt-Stramann (2005), Laban (1978) e Gomes-da-Silva (2011), comungamos da tese de que o movimento é gesto, dotado de significado, não correspondendo este à tradução da representação, mas à operaçáo existencial, por participar da mudança de coordenadas enviadas ao esquema corporal. Logo, referenciando Gomes-da-Silva, ao tratarmos da significaçáo do movimento, da atmosfera criada por ele, do horizonte de expressáo do corpo situado no mundo, já estamos no âmbito da corporeidade (2011, p. 29).

A partir do dito, é natural para nós pensarmos em linguagem ao falarmos de movimento. Isso porque movimento é expressão, é comunicação. Obviamente há movimentos que são interiorizados, sem uma eloquência perceptível, tal como o tônus dos nossos músculos, o batimento do nosso coração, o pulsar de nossas veias e artérias. Contudo, se transcendermos compreensóes tradicionalistas (corpo fisiológico, mecânico), podemos ainda assim discutir sobre possíveis comunicaçóes desses movimentos. Mas deixemos para outra oportunidade.

Prosseguindo o raciocínio, a linguagem está no movimento tal como a visão está no olhar. Isto é, o movimento configura-se por um emaranhado de informações que podem ser decodificadas e, por conseguinte, assimiladas como mensagens, portanto, comunicação. Afirmamos isso baseados na conjuntura comunicativa que temos enquanto seres sociais, que interagem por meio de inúmeras e diferentes comunicaçôes. A questáo é que ainda é minoritária a percepçáo do movimento enquanto linguagem.

Pensando pelo prisma da corporeidade, o movimento não se encontra isolado em si, mas em meio às relaçóes estabelecidas pelos sucessivos gestos. Da mesma forma, o movimentar-se humano não possui significação imanente, ele se limita a indicar certa relação entre o homem e o mundo sensível. No movimento, homem e mundo sensível transformam-se numa unidade. Isso quer dizer que "[...] o mundo é sempre mundo vivido e o movimento é sempre gesto com sentido/significado para quem individual ou coletivamente o praticou" (Gomes-da-Silva, 2011, p. 37).

O fato é que nossos gestos revelam muitos mais do que aparentemente percebemos. O corpo, de uma forma geral, é depositário de códigos condizentes com a cultura que temos. Por isso, nossas açóes são próprias das condutas instintivas e representantes daquilo que 
aprendemos e assimilamos ao longo dos anos. Daí nosso movimentar não ser neutro, mas vinculado a um interesse cultural, formando, inclusive, o sujeito social. Isso, de uma forma ou de outra, garante a utilidade e ajustamento por meio do abrandamento das emoçóes e arrefecimento do poder do corpo.

Ao tratarmos de comunicação corporal, priorizamos a comunicação efetuada por meio da linguagem náo verbalizada. Apesar de entendermos por comunicaçáo corporal a que se faz por meio do corpo, verbal ou não, nossa ênfase escoa na expressão dos gestos, na postura tida pelo sujeito, na ocupação do espaço no qual se insere. Portanto, os fundamentos aqui apresentados são subsidiados pela ação comunicativa corporal não verbal. A razão disso justifica-se pela intencionalidade de ampliar o mover-se para comunicar-se. Ou seja, para que o sujeito se expresse, ele, neste contexto que apresentamos, deverá, antes de qualquer coisa, ser consciente de sua capacidade de comunicação não verbal.

Tendo em vista que a questáo norteadora do estudo fomenta a busca pela decodificação das configuraçóes da comunicaçáo corporal no ato docente, é pertinente elucidarmos um pouco do contexto no qual o professor está inserido, ressaltando questóes referentes à comunicação corporal estabelecida (ou não) por ele com seus alunos. Dificilmente o professor pode se comunicar, interagir com os alunos, sem que o gesto corporal náo se atrele à linguagem verbal. Contudo, nos cursos de formação de professor, por exemplo, a noção de corpo, no processo de ensino-aprendizagem, é ainda muito vaga, apresentando-se como uma simples matéria, um "envelopamento da mente”, como provoca Picard (1986).

$\mathrm{Na}$ direção contrária, estamos alertando os professores para compreenderem que a comunicação entre eles e os alunos pode ser otimizada se desencadearem um processo comunicativo mais consciente, por isso mesmo mais fluente e eficaz. Contrariando a compreensão do corpo como envelopamento da mente, destacamos a comunicação corporal como ferramenta poderosa, equivalente ao poder da palavra, para criar uma ligaçáo com o conhecimento informado. Isso porque sabemos que o comportamento náo verbal pode perfeitamente repetir, contradizer, substituir, complementar, acentuar ou regular o comportamento verbal (Knapp; Hall, 1999).

Por isso, evidenciamos a necessidade de os profissionais de educação, especificamente os que atuam no âmbito escolar, consi- 
derarem a comunicação do corpo, a fim de serem mais eficientes no desenvolvimento de suas atividades. $\mathrm{O}$ fato é que ainda são escassos os trabalhos que estudam a relação corpo-movimento-comunicação, sob uma intenção de ativar a percepção dos sinais não verbais em busca do melhoramento da açấo interventiva do professor.

Sobre esse caráter profissional, Knapp e Hall (1999), ao discutirem os trabalhos sobre a habilidade de profissionais (médicos, professores, psicólogos), comentam que aqueles que se ocupam de condutas não verbais obtêm maior pontuação em sua competência profissional. É justamente nesse sentido que caminhamos com nossa proposta, procurando excitar os educadores a atentar para o real valor do aprimoramento sensitivo da comunicaçáo corporal, para uma docência mais comunicativa e, portanto, mais interativa e integrativa. Isso porque acompanhamos o que dizem Pease e Pease: "[...] entendendo o que o corpo diz, entendemos melhor o que os outros nos têm a dizer" (2005, p. 48).

Contudo, nossa abordagem da comunicação corporal não se restringe aos canais comunicativos - se bem que só esse aspecto já é por demais abrangente -, mas também compreendemos a comunicação como um diálogo entre o homem e o mundo (Weil; Tompakow, 1986). O movimentar-se é uma forma da existência, em que se tem os próprios valores e onde o homem realiza sua expressividade (Gomes-da-Silva, 2011).

Defendemos que os movimentos humanos em sala de aula não se reduzem à funcionalidade das tarefas docentes, mas se constituem em mensagem, transmitem uma intençáo educativa. A pesquisa de Costa et al (2012, p. 219-238), por exemplo, demonstrou que o andar do professor revela sua atitude pedagógica, tendo identificado que, para cada ato específico, conduzir a turma, disciplinar os alunos e organizar a aula, a qualidade do andar do professor muda.

Desse modo, realçamos a intencionalidade dos atos corporais do professor em sala de aula. Mesmo que sejam inconscientes para ele, esses atos estão comunicando suas mensagens. A busca é para que os professores tomem consciência do sentido comunicativo dos seus movimentos em sala de aula. Ao contrário da teoria e prática da educaçáo hegemônica, que trata os movimentos como destrezas ou habilidades motoras padronizadas, concebemos o movimento pela linguagem. Sendo assim, posturas, posiçóes, deslocamentos, feições, roupas, objetos "[...] não são tomados como fragmentos inocentes da comunicação, 
mas como constituintes de configuraçôes múltiplas e cambiantes de uma teia de significados. Os movimentos e os não-movimentos são identificados como dizíveis" (Gomes-da-Silva, 2011, p. 335).

\section{Decodificando as Açóes Corporais}

A comunicação vai muito além do saber falar, saber escrever, ou seja, saber verbalizar. A comunicação caracteriza-se pela ação interativa entre duas ou mais partes. Contudo, ela pode ser expressa das mais diversas formas. Comunicar-se é informar ao outro, de antemáo, sobre a existência do eu, mostrar que tal informação advém de algo/ alguém concreto, pensante, existencial. Para tanto, a linguagem não verbal, tal qual a verbal, tem profundo valor. Nos tempos de hoje, cada vez mais corridos, conturbados, negligenciamos a comunicação do nosso corpo, valorizando táo somente aquela que ouvimos, lemos, mas não a que expressamos.

Baseamo-nos na perspectiva trazida por Corraze (1982), que afirma ser a comunicação não verbal um meio, dentre outros, de transmitir informação, não se valendo de linguagem escrita, falada ou seus derivados não sonoros (linguagem dos surdos, por exemplo). De acordo com o autor, para o ser humano, as comunicaçóes náo verbais se processam através de três suportes: (a) corpo, por meio de suas qualidades físicas, fisiológicas e movimentos; (b) homem, por meio dos objetos associados ao corpo, como os adornos, as roupas, ou mesmo as mutilações (marcas, cicatrizes, tatuagens); e (c) dispersão dos indivíduos no espaço, por meio do englobamento do espaço físico que cerca o corpo até o espaço que a ele se relacione, o espaço territorial.

Intervindo diretamente no corpo, registramos as diversas possibilidades que podemos ter ao atuarmos de forma a explorar a capacidade comunicativa corporal. Desse modo, o professor, alvo central de nossa intervenção, tendo consciência de seus potenciais corporais, comunica-se, expressa-se e educa mais efetivamente. Todavia, é fundamental que avancemos para além do aspecto da instrumentalidade, ou ainda, um conjunto de órgáos, sistemas ou o objeto de programas de promoção de saúde ou lazer.

Entendemos que o corpo é a instância primária de toda a significação do homem no mundo, estando estes dois elementos em constante relaçáo, ora equilibrada, ora em total desequilíbrio. Sendo assim, ligarmo-nos ao nosso corpo além do aspecto natural da vida 
é tornar mais perceptíveis nossas transformaçóes, nossas mudanças, nossas modificaçóes corporais. Notarmos que nosso corpo, com o tempo, não é mais o mesmo é um fato inegável.

Consubstanciados em Josso (2012), sustentamos a ideia de que, para acessar efetivamente o corpo falante, portanto comunicativo, é preciso aprender a colocar-se em contato, em primeiro momento, com um conhecimento pré-reflexivo para acolher o que ocorre numa interioridade encarnada no movimento interno e nos conjuntos teciduais, para entâo integrar essa doação. Segundo Josso, "[...] é preciso deixar sobrevir uma ressonância, escutar o que o corpo tem a dizer" (2012, p. 27), estar atento às sensaçóes, qualificando-as de modo a dar-lhes valor.

Por conseguinte, para que haja de fato uma decodificação das ações advindas do corpo comunicativo, é necessário estabelecer com ele uma confidente relação transcendental e, por consequência, considerar suas possibilidades, respeitar suas limitaçóes, confiar em sua potencialidade relacional. Assim, compreendendo os fatores inerentes a esse processo e assimilando suas contribuiçôes, é viável mudar-se, transformar-se corporalmente. O homem é corpo e o corpo é homem. Aceitando e assimilando tal pensamento, é possível, de forma natural e espontânea, exprimir-se corporalmente, mostrar-se fidedignamente.

Recorremos à comunicaçáo corporal, creditando a ela a possibilidade de uma mudança, uma efetiva transformaçáo no ato de educar. Aclaramos a importância da intervençáo focada no corpo do professor, bem como a relevância em considerar a comunicação corporal no processo de ação comunicativa do sujeito com o meio que o entorna. $\mathrm{O}$ corpo, quando trabalhado adequadamente, pode se mostrar surpreendentemente contribuinte para a ação relacional do sujeito social. Logo, considerar a comunicaçáo corporal como elemento fundamental para tal acontecimento é revelar ao sujeito a potencialidade da linguagem não verbal e suas efetivas implicaçóes.

Guiados por essa concepção, percebemos que o professor inserese, por meio de sua individualidade e peculiaridade, na construçáo do processo pedagógico como um todo. Isso garante a diversidade de olhares contribuindo para a ampliaçáo das possibilidades e a construçáo de outros novos saberes. A partir do dito, torna-se importante e essencial levar em consideração o conhecimento do trabalho dos professores, seus saberes cotidianos. Tal postura rompe com o tradicionalismo que sustenta a ideia de que professores nada mais são do que transmissores de saberes produzidos por outros grupos. 
Sob o prisma da comunicaçáo corporal, o ato de movimentarse toma maiores proporçóes do que aquelas convencionais do nosso cotidiano. Isso significa irmos além do deslocamento, da postura mais confortável, do mover-se por alguma necessidade. Promovemos a compreensão dos significados do vocabulário corporal, para assim poder ampliá-los e compartilhá-los. Em se tratando especificamente da esfera educacional, apoiamo-nos no pensamento de Gomes-daSilva (2011), afirmando que, neste contexto, a linguagem corporal deve ser ensinada e instrumentalizada em prol de uma melhor interação entre educador e educando. Dessa forma, é possível que “[...] eles, os educadores e educandos, façam novos arranjos nos repertórios motores e nas representaçóes sociais que possuem" (2011, p. 336).

Preocupa-nos a textualidade corporal, as informaçóes que a todo o momento estáo em trânsito, oferecendo aos olhos mais atentos uma compreensão da realidade que, por muitas vezes, opera-se disfarçadamente, encontrando no medo, no receio, na timidez, o abrigo perfeito para continuar recolhida. Para isso, conclamamos a atenção aos indícios que o corpo oferece, não apenas os mais visíveis, perceptíveis a todo e qualquer olhar. Referimo-nos àqueles que são ofuscados pela avalanche de informaçóes que temos na contemporaneidade, sobretudo devido a esta massificação tecnológica, das informaçôes instantâneas e voláteis.

Somos seres naturalmente comunicativos e, por isso, precisamos estar atentos às informaçóes que emergem não só da fala, da escrita, mas dos sinais particulares do corpo em si, através de seus pormenores, seus vestígios linguísticos. A isso denominamos léxico corporal, ou seja, o repertório de informaçóes emergido do movimento, dos gestos, da expressividade corporal. Desconsiderar tais sinais é, no mínimo, omitir-se das informaçóes que evidenciam de fato quem somos. Neste aspecto, remetemo-nos a Merleau-Ponty, o qual fundamenta que "[...] o uso que um homem fará de seu corpo é transcendente em relação a esse corpo enquanto ser simplesmente biológico" (1994, p. 257).

\section{Consideraçóes Finais}

Evidenciamos, no discorrer do estudo, nossa concepçáo de comunicação por meio do corpo, fundamentando-a por meio de aspectos que corroboram para o entendimento aqui defendido, 
sobretudo a comunicação corporal enquanto um saber docente. Tal entendimento se fortifica por constituir-se de perspectivas educacionais que são inerentes ao processo de ensino e aprendizagem. Compreendemos que o saber docente está diretamente ligado a uma relação pedagógica centrada nas necessidades e interesses do processo ensino-aprendizagem. Nesse contexto, a especificidade do saber docente ultrapassa a formaçáo acadêmica, abarcando a prática cotidiana e a experiência vivida daquele que educa.

Estendendo a compreensão abordada neste estudo, aclaramos que o corpo se faz extremamente significativo para o processo educacional, visto principalmente sua evidenciação daquilo que pode ou não estar comprometendo a boa comunicaçáo entre professor e aluno. Partimos em defesa de que, ampliando a capacidade comunicativa corporal, é possível aprender as linguagens e, ao mesmo tempo, adquirir a capacidade de modificá-las. Deste modo, possibilitar uma otimização da ação docente por meio da comunicação corporal é, na verdade, maximizar a competência de comunicaçáo do mesmo.

Neste contexto, arguimos sobre a perspectiva que cremos ser a mais completa e mais justa perante o valor do corpo. Sua significância está diretamente ligada ao processo de desenvolvimento humano, passando pelo estar e fazer-se perceber no meio em que se insere. $\mathrm{O}$ homem não está no corpo, nem o corpo está no homem. Ambos são um só elemento, o qual só pode ser compreendido se considerado tanto objetivamente como por meio de sua essência subjetiva.

Ligarmo-nos ao nosso corpo além do aspecto natural da vida é tornar mais perceptíveis nossas transformações, nossas mudanças, nossas modificaçóes corporais. Notarmos que nosso corpo, com o tempo, não é mais o mesmo, é um fato inegável. No entanto, estabelecer com ele uma confidente relação transcendental é, por consequência, considerar suas possibilidades, respeitar suas limitaçóes, confiar em sua potencialidade relacional. Procuramos evidenciar que tais fatos são reais e que podem ser aplicados de maneira sistemática. Sendo assim, referenciando o aspecto educacional no qual nos propomos a aprofundar, é preciso que o professor tome consciência de seu corpo para assim melhor explorá-lo. Para isso, é primordial que ele se veja no ato docente, enxergando sua interaçáo comunicativa com o outro e com o meio. 


\section{Nota}

${ }^{1}$ Tradução livre do autor deste artigo.

\section{Referências}

ANTÉRIO, Djavan. Repercussóes Pedagógicas na Capacidade Comunicativa Corporal do Educador. 2011. Dissertação (Mestrado em Educação) - Programa de Pós-graduação em Educação, Universidade Federal da Paraíba, João Pessoa, 2011.

ANTÉRIO, Djavan; GOMES-DA-SILVA, Pierre Normando. Corpo Comunicativo: analisando a comunicação corporal por meio da exploração espacial do educador. Motrivivência, Florianópolis, Universidade Federal de Santa Catarina, v. 41, p. 206-222, 2013.

ARGYLE, Michael. Bodily Communication. New York: Methuen \& Co., 1988.

BOMBASSARO, Ticiane; VAZ, Alexandre Fernandez. Sobre a Formação de Professores para a Disciplina Educação Física em Santa Catarina (1937-1945): ciência, controle e ludicidade na educação dos corpos. Educar, Curitiba, Universidade Federal do Paraná, n. 33, p. 111-128, 2009.

CORRAZE, Jacques. As Comunicaçóes Não-verbais. Rio de Janeiro: Zahar, 1982.

COSTA, Sandra Barbosa et al. A Linguagem Expressiva do Andar Humano. In: CATTUZZO, Maria Tereza; CAMINHA, Iraquitan de Oliveira (Org.). Fazer e pensar Ciência em Educaçáo Física - Livro 1. Joāo Pessoa: Universidade Federal da Paraíba, 2012.

FREIRE, João Batista. Educaçáo de Corpo Inteiro: teoria e prática da Educação Física. São Paulo: Scipione, 2009.

FREIRE, Paulo. A Educaçáo como Prática da Liberdade. Rio de Janeiro: Paz e Terra, 1999.

FREIRE, Paulo. Pedagogia da Autonomia. Rio de Janeiro: Paz e Terra, 1999.

FREIRE, Paulo. Pedagogia do Oprimido. São Paulo: Paz e Terra, 2003.

GOMES-DA-SILVA, Pierre Normando. O Jogo da Cultura e a Cultura do Jogo: por uma semiótica da corporeidade. Joáo Pessoa: Universidade Federal da Paraíba, 2011.

HILDEBRANDT-STRAMANN, Reiner. Teoria e Prática da Oficina de Movimento. Movimento, Porto Alegre, Universidade Federal do Rio Grande do Sul, v. 11, n. 1, p. 121-139, jan./abr. 2005.

JOSSO, Marie-Christine. O Corpo Biográfico: corpo falado e corpo que fala. Educaçáo \& Realidade, Porto Alegre, Universidade Federal do Rio Grande do Sul, v. 37, n. 1, p. 19-31, jan./abr. 2012.

KNAPP, Mark; HALL, Judith. Comunicaçáo Não-verbal na Interaçáo Humana. São Paulo: JSN, 1999.

LABAN, Rudolf. Domínio do Movimento. São Paulo: Summus, 1978. 
MEDINA, João Paulo Subirá. A Educação Física cuida do Corpo... e "Mente”. Campinas: Papirus, 2001.

MEDINA, João Paulo Subirá. O Brasileiro e seu Corpo. Campinas: Papirus, 2002.

MERLEAU-PONTY, Maurice. Fenomenologia da Percepçáo. São Paulo: Martins Fontes, 1994.

MINAYO, Maria Cecília de Souza. O Desafio do Conhecimento: pesquisa qualitativa em saúde. 11. ed. São Paulo/Rio de Janeiro: Hucitec/Abrasco, 2008.

MINAYO, Maria Cecília de Souza (Org.). Pesquisa Social: teoria, método e criatividade. Petrópolis: Vozes, 2001.

PEASE, Allan; PEASE, Barbara. Desvendando os Segredos da Linguagem Corporal. Rio de Janeiro: Sextante, 2005.

PICARD, Dominique. Del Código al Deseo: el cuerpo en la relación social. Buenos Aires: SACIF, 1986.

RECTOR, Mônica; TRINTA, Aluizio Ramos. A Comunicação Náo-verbal: a gestualidade brasileira. Petrópolis: Vozes, 1985.

RECTOR, Mônica; TRINTA, Aluizio Ramos. Comunicaçáo do Corpo. São Paulo: Ática, 1999.

WEIL, Pierre; TOMPAKOW, Roland. O Corpo Fala: a linguagem silenciosa da comunicação não-verbal. Rio de Janeiro: Vozes, 1986.

Djavan Antério é professor pesquisador do Grupo de Estudos e Pesquisas em Corporeidade, Cultura e Educação (GEPEC), doutorando e mestre em Educação pela Universidade Federal da Paraíba (UFPB). Dedica-se às pesquisas na área da Educação, enfatizando a Educaçáo Física e a Arte no contexto educacional. Prioriza estudos voltados à formação e prática docente; às relaçôes sociopedagógicas; e à pedagogia do movimento, realçando a ação comunicativa corporal.

Email: djavananterio@gmail.com

Recebido em 19 de abril de 2013 Aceito em 03 de fevereiro de 2014 